\title{
NOx Emission Reduction Using Hydrous Ethanol-Gasoline Blend with Syngas in SI Engine
}

\author{
Ahmed A. Al-Harbi*, Saud A. Binjuwair, Ibrahim A. Alshunaifi, Abdullah M. Alkhedhair, \\ Abdullah J. Alabduly, Mohammed S. Almorat, Miqad S. Albishi
}

King Abdulaziz City for Science and Technology (KACST), Riyadh, KSA

Email: *ahalharbi@kacst.edu.sa

How to cite this paper: Al-Harbi, A.A., Binjuwair, S.A., Alshunaifi, I.A., Alkhedhair, A.M., Alabduly, A.J., Almorat, M.S. and Albishi, M.S. (2019) NOx Emission Reduction Using Hydrous Ethanol-Gasoline Blend with Syngas in SI Engine. Journal of Environmental Protection, 10, 1278-1298. https://doi.org/10.4236/jep.2019.1010076

Received: September 8, 2019

Accepted: October 7, 2019

Published: October 10, 2019

Copyright $\odot 2019$ by author(s) and Scientific Research Publishing Inc. This work is licensed under the Creative Commons Attribution International License (CC BY 4.0).

http://creativecommons.org/licenses/by/4.0/

(c) (i) Open Access

\begin{abstract}
This paper presents a comparatively experimental study of nitrogen oxide (NOx) emissions from an internal combustion engine fed by gasoline available in the Saudi Arabian market rating octane number (RON 91 and RON 95) with admixtures of syngas with $0 \%$ E0, 5\% E5 and 10\% E10-by volume of pure ethanol-and HE5 and HE10 with water concentrations of 5\%, 10\%, $30 \%$ and $40 \%$-by volume of hydrous ethanol-at stoichiometric mixtures. An on-board plasma system used to produce syngas through the partial oxidation of gasoline with air in a plasma-assisted fuel reformer. The syngas injected in a gasoline engine with a fuel injection system modified for operation with addition of some amount of syngas. The experimental results demonstrated a significant total reduction in NOx emissions and slightly increased in fuel consumption when mixing gasoline (RON 91 and RON 95), ethanol (E5 and E10) and hydrous ethanol (HE5 and HE10) with syngas. For the use of hydrous ethanol (HE5 and HE10) along with the addition of syngas, for both RON 91 and RON 95, the lowest NOx emissions are found 72\% with a water concentration of $40 \%$.
\end{abstract}

\section{Keywords}

Plasma, Fuel Reforming, Syngas Production, Ethanol, Emissions, Nitrogen Oxides

\section{Introduction}

Strict regulations on environmental protection have attracted researchers to address reductions in emissions from engines such as hydrocarbons $\mathrm{HC}$, nitrogen oxides $\mathrm{NOx}$, carbon dioxide $\mathrm{CO}_{2}$ and carbon monoxide $\mathrm{CO}$. Emissions from en- 
gines are considered a major cause of global warming and have direct effects on human health as undesirable emissions generated by the combustion process of ICEs are expelled into the environment. There are current problems with limited fossil fuel resources and worldwide heating phenomena, so researchers are interested in using alternative fuels and preserving the environment. Based on recent research to produce more sustainable fuel for the automotive industry, ethanol is often mixed with gasoline. This process becomes more sustainable if hydrous ethanol is used instead of anhydrous ethanol; therefore, that energy can be saved [1]. Based on experiments using a fuel mix of ethanol and gasoline, fuel consumption and torque production did not change or increase slightly, and carbon monoxide (CO) and hydrocarbon (HC) emissions dropped significantly. It has been observed that changes in nitrogen oxide ( $\mathrm{NOx})$ emissions are influenced by the operation of the engine rather than the ethanol content. Changes can be observed with the exception of reductions in NOx emissions compared with traditional gasoline fuel [2]. In general, bioethanol and ethanol are more interactive than hydrocarbon gasoline. These compounds include hydroxyl roots such as carbon bonds and polar fracture, and fuel compounds contain nitrogen.

NOx is formed when the effect of hydrous ethanol in the engine is to reduce pressure, and water absorbs heat. During combustion, water absorbs heat and evaporates to reduce temperature and then reduce NOx emissions. When comparing, we note the differences between an anhydrous ethanol mix with gasoline and a hydrous ethanol mix with gasoline at an average level $(0 \%-40 \%$ water volume). The NOx emissions for the hydrous ethanol mix with gasoline are less than those for the anhydrous ethanol mix with gasoline. Water in hydrous ethanol also reduces pressure, temperature and combustion speed compared with that in anhydrous ethanol. In addition, the increased water content of hydrous ethanol improves NOx emissions. Engine speed affects NOx emissions so that more fuel is burned, the temperature increases and NOx emissions increase if the engine speed increases. Oxidation converts nitrogen into NOx during the combustion process. Moreover, this process is associated with hydrocarbon oxidation and chemical kinetics. In addition, when the nitrogen content of the fuel increases, the amount of NOx increases. Many studies have also shown that when using ethanol-gasoline blends, increasing ethanol content reduces NOx emissions. The main reason for the reduction in NOx emissions is the greater heat evaporation of ethanol in comparison to gasoline. In addition, the temperature of the mixture during combustion is reduced. The effect of gasoline-ethanol mixture emissions with different ethanol ratios has been investigated, and the particle diameter in the assembly is smaller. When the ethanol concentration increases, the aerosol concentration decreases, leading to complete combustion. For this reason, there is a reduction in emissions of nitrogen oxides and carbon monoxide. Anhydrous ethanol fuel tends to have the same properties as ethanol fuel due to the oxygen content in ethanol. The total mixture burns at a stoichiometric mixture when the engine is operating [3] [4]. 


\begin{tabular}{|c|c|c|c|}
\hline \multicolumn{4}{|c|}{ Nomenclature: } \\
\hline ICE & Internal combustion engine & HE5 & Hydrous ethanol 5 \\
\hline $\mathrm{CO}$ & Carbon monoxide & HE10 & Hydrous ethanol 10 \\
\hline $\mathrm{CO} 2$ & Carbon dioxide & WC & Water concentration \\
\hline E5 & Ethanol 5 & AEAC & Anhydrous ethanol fuel \\
\hline E10 & Ethanol 10 & $\mathrm{AEHC}$ & Hydrous ethanol fuel \\
\hline MFB & Mass fraction burned & NOx & Nitrogen oxide \\
\hline $\mathrm{HC}$ & Hydro carbon & DC & Direct current \\
\hline$\lambda$ & Lambda & $\mathrm{SO}_{2}$ & Sulfur dioxide \\
\hline ECU & Engine control unit & PPM & Parts per million \\
\hline RON 91 & Rating octane number 91 & RON 95 & Rating octane number 95 \\
\hline G 91 & Gasoline 91 & G95 & Gasoline 95 \\
\hline EPA & Environment protection agency & FI & Fuel injection \\
\hline GHG & Greenhouse gases & E0 & Gasoline \\
\hline SI & Spark ignition & MBT & Maximum brake torque \\
\hline THC & Total hydrocarbon & $\mathrm{H}_{2}$ & Hydrogen \\
\hline IC & Internal combustion & $\mathrm{CU}$ & Control unit \\
\hline $\mathrm{O} 2$ & Oxygen & PC & Personal computer \\
\hline RPM & Revolution per minute & Syngas & Synthesis gas \\
\hline OHV & Overhead value & ${ }^{\circ} \mathrm{C}$ & Celsius \\
\hline BSFC & Brake specific fuel consumption & $\mathrm{NO}_{2}$ & Nitrogen dioxide \\
\hline
\end{tabular}

In 2008, a study in Brazil conducted by Orlando Volpato Filho reviewed the process of producing Gasoline C (E22) using hydrous ethanol (AEHC, E100) instead of anhydrous ethanol (AEAC) without water separation. According to this paper, there are two types of ethanol used as automotive fuels: anhydrous ethanol fuel (AEAC) and hydrous ethanol fuel (AEHC). Hydrous ethanol can be produced by easy drops, while otherwise dry conditions are needed to produce anhydrous ethanol. Gasoline $\mathrm{C}$ can be made by mixing anhydrous ethanol fuel (AEAC) with gasoline (E0). The purpose of mixing is to produce Gasoline C with a very low separation temperature (below $-30^{\circ}$ Celsius). However, hydrous ethanol fuel (AEHC, E100) can be used in particular climate conditions to make Gasoline C without water phase separation. To prevent water separation, an alcohol is added to the mixture to reduce the separation temperature. For example, a mixture called EHi22 is made by adding isopropanol to $\mathrm{EH} 22$, and then the mixture separation temperature will drop from $-30^{\circ}$ to $-100^{\circ}$ Celsius. The study showed that greenhouse gas (GHG) emissions from the production of anhydrous ethanol are approximately $436 \mathrm{~kg} \mathrm{CO}_{2} / \mathrm{m}^{3}$ of ethanol, while those from hydrous ethanol are $417 \mathrm{~kg} \mathrm{CO} / \mathrm{m}^{3}$. Therefore, by switching to AEHC, approximately 85 billion $\mathrm{kg} \mathrm{CO}_{2}$ per year of GHG emissions can be avoided. On average, ethanol productivity from one ton of sugar cane is 85 litres of AEAC and 90 
litres of AEHC. To produce AEHC, the process requires approximately $2.7 \mathrm{MJ} / \mathrm{l}$ of ethanol, while more complex processes that consume approximately $2.9 \mathrm{MJ} / \mathrm{l}$ are needed to produce AEAC. The study suggested using the energy saved from the dehydration of AEHC to produce electricity. In summary, the use of AEHC instead of AEAC will reduce GHG emissions, improve energy efficiency, and allow extra electricity to be sold, and for new plants, lower capital cost can be achieved, leading to more inexpensive Gasoline C [5].

Munsin et al. investigated the effects of using hydrous ethanol with increasing water content (above $40 \%$ by volume) on the spark ignition engine emissions and rendering for different loads and water contents in ethanol. The results were presented for an engine speed of $3600 \mathrm{rpm}$ and the stoichiometric condition, and ethanol with 5\% water content had lower HC and NOx emissions than the Environmental Protection Agency boundary pattern in 2011 after the catalytic transformer. In contrast, prior to the catalytic transformer, $\mathrm{HC}+\mathrm{NOx}$ emissions were higher than the Environmental Protection Agency boundary; however, CO was lower than the Environmental Protection Agency boundary in both cases. In addition, increasing the load increased the overall efficiency and NOx emissions, but the brake-specific fuel consumption (BSFC) and the HC, acetaldehyde and formaldehyde emissions decreased. The study revealed that at a constant load, increasing water content decreases the emissions of nitrogen oxides and total efficiency and increases CO, HC, BSFC, acetaldehyde and formaldehyde emissions. A catalytic converter is recommended when using hydrous ethanol because it reduces all emissions. It is worth pointing out that using hydrous ethanol had negative effects on the engine materials, lubricant and fuel system, such as oxidation of engine parts and lubricity failure [6].

El-Faroug et al. discussed the stability of ethanol-gasoline-water blends; the properties of hydrous ethanol along with those of its mix with gasoline; and their effect on the combustion properties, emissions and engine rendering in spark ignition (SI) engines. Almost all results showed refinement in combustion properties and improved engine rendering by using hydrous ethanol. Hydrous ethanol has a higher octane count than that of gasoline, resulting in a higher compression ratio. In addition, using hydrous ethanol (with low water content) improves combustion efficiency, cylinder pressure, heat release rate, flame speed and cylinder temperature. However, it reduces the duration of combustion, directional engine knocking and temperature of combustion. In terms of engine rendering and brake power, the results showed refinement in the torque, thermal brake efficiency and mean effective pressure brakes when using hydrous ethanol. According to the study, increasing the water content in the mixture allows the ignition points to advance to the maximum brake torque (MBT) condition and results in an increase in the engine torque and power output. However, water content above $30 \%$ had an adverse impact on engine rendering. Therefore, it was revealed that E70W30 fuel is a good substitute fuel for engine performance and cost. It was presented that hydrous ethanol blends have lower NOx emissions than gasoline and anhydrous ethanol blends. Furthermore, a small reduction in 
$\mathrm{CO}, \mathrm{CO}_{2}$ and unburned $\mathrm{HC}$ emissions was observed. Moreover, high water content lowered the combustion temperature, leading to higher amounts of unburned HCs. However, acetaldehyde and formaldehyde emissions were relatively higher than those from gasoline, while emissions of nitrogen oxides decreased with increasing water content [7].

De Melo et al. examined the effect of adding hydrous ethanol to E25 on the characteristics of the combustion of flexible fuel engines and emissions under different operating conditions. The study identified gasoline E25 as H0 and hydrous ethanol as $\mathrm{H} 100$. These fuels were mixed by volume to produce $\mathrm{H} 30$, $\mathrm{H} 50$ and H80. According to this paper, increasing ethanol content caused an increase in the maximum pressure in the cylinder for fuel-rich conditions (torque of $105 \mathrm{Nm}$ ) because the high octane number of ethanol allows the spark timing to progress. However, for the case of the stoichiometric condition (torque of 60 $\mathrm{Nm}$ ), most of the spark timing and pressure were maintained at the same scale except at the speed of $3875 \mathrm{rpm}$. For such torque and speed, engine knocking restricted the spark timing from reaching the MBT for the $\mathrm{H} 0$ and $\mathrm{H} 30$ fuels. One of the combustion characteristics covered by the study was combustion duration, which did not present any significant changes with ethanol addition except for $\mathrm{H} 0$, which presented a higher value for $60 \mathrm{Nm}$ torque. It was observed that ethanol addition increases the specific consumption, shifts the mass fraction burned (MFB) and changes the crank angle of the maximum pressure due to the increase in the spark timing angle. Ethanol addition increases energy efficiency except from $\mathrm{H} 30$ to H50, where it drops. For the addition of ethanol above 50\%, H30 presented high energy efficiency. However, the highest energy efficiency observed among all fuels was for H100 for the whole operating conditions. The results showed a reduction in the total hydrocarbon (THC) and $\mathrm{CO}$ emissions with ethanol addition but increased emissions of $\mathrm{CO}_{2}$, unburned ethanol and aldehydes. NOx emissions presented a different behaviour. These emissions decreased with ethanol addition at low speeds of $1500 \mathrm{rpm}$ to $2250 \mathrm{rpm}$ and increased at high speeds of $4500 \mathrm{rpm}$. However, for both operating conditions, ethanol content above 50\% did not show important changes in NOx emissions. In addition to the effects of fuel and speed, a high load $(105 \mathrm{~m})$ produces less NOx emissions [8].

Huang et al. investigated the integration of oxygen in mixtures with the addition of ethanol is studied for reducing hydrocarbon (HC) and carbon monoxide (CO) emissions and increasing combustion efficiency. Moreover, mixing anhydrous ethanol at higher temperatures makes the mixture better and combustion more complete. Mixing hydrous ethanol will reduce the stability of the blended fuel. Hydrogenated ethanol can be used because it is a promising substance for gasoline and is more popular because of reduced harmful emissions and energy conservation [9].

The role of ethanol in the engine is to burn the rich air-fuel mixture, and through combustion, ethanol generates higher production capacity than gasoline. Additionally, a smaller amount of non-burning hydrocarbons and NOx is 
emitted due to the lower heating value, leading to increased fuel consumption of ethanol. It was observed that with increasing concentration of water, the ignition timing should be developed to ensure sufficient water evaporation. It was also observed that emissions are low in NOx and contain a high proportion of water because high temperature leads to evaporation of water and low temperature of the cylinder [10].

Reforming is a scientifically proven process for cracking complex chemical compounds. Research confirms that fuel reuse and the decomposition of complex hydrocarbons into syngas can be used to control the combustion process. Tar conversion also has a beneficial effect on fuel repair as a process of tar removal. The use of ethanol allowed easier conversion of isooctane. The conclusion was that ethanol content had a significant impact on the conversion and transitional reforming of fuel with different ethanol ratios and the impact of reforming performance. Reforming can be split into two main groups: non-catalytic and catalytic reforming. One type of non-catalytic reforming involves the high-temperature cracking of chemical compounds. A second type of non-catalytic reforming is interesting in that plasma repair is performed to produce hydrogen. Reforming is widely carried out in the energy industry [10]. Different types of advanced devices are used in reforming for hydrogen production. For example, Heywood et al. developed a plasmatron device to generate hydrogen with the help of plasma, and the device was demonstrated in an SI engine with gasoline to significantly decrease NOx emissions by $80 \%$ and increase the efficiency of the engine. Hydrogen is effective in engine fuel for obtaining a low flame temperature to reduce NOx emissions [11].

The researchers combined the engine and internal combustion to operate the engine using gasoline as a main fuel blended with hydrogen gas created by the reformer. In this way, emissions of exhaust gases, fuel consumption and engine efficiency can be reduced. However, it is necessary to examine the following parameters: operating temperature, cold start time, fuel type and hydrogen content in the syngas [9]. It is necessary to increase engine efficiency and reduce vehicle emissions for better gas reduction and air quality. The SI engine emissions can be reduced by adding hydrogen by a plasmatron, which is an electric gas heater that uses gases to react at a high temperature to produce a syngas containing hydrogen. In addition, among the concepts to reduce emissions is the generation of hydrogen by microplasmatron, which is used onboard. The plasmatron works by controlling high temperature to heat the gases and partially ionize them at a high temperature to form cold plasma. The plasmatron is then mixed, and the hydrocarbon fuel reforming process produces a syngas that contains hydrogen. Using this method, many types of fuels can be repaired and converted to syngas using plasma at high temperature and production of syngas $\left(\mathrm{H}_{2}+\mathrm{CO}\right)$ [12] [13] [14] [15].

Hoang et al. [16] studied the gasoline with ethanol at different percentages. The fuel was mixing with E5 and E10 to analyze engine emission characteristics. The emission of nitrogen oxides was formed at a high temperature of $1500^{\circ} \mathrm{C}$ in 
the combustion process. In addition, Results indicated that NOx emission decreased when using E5 and E10 compared to the original gasoline and E5 had less emission in NOx compared to E10. The study stated that the main factor in the change in NOx, emission concentration was the effect of ethanol on the temperature in the combustion chamber.

Xiaokang et al. [17] investigated experimentally performance, exhaust noise, and emission products of a gasoline engine operated with hydrous ethanol gasoline with 10\%, 20\% hydrous ethanol by volume (E10W and E20W) and pure gasoline (E0). The tests-that were performed at different engine speeds-showed that as the engine speed is increased, pure gasoline showed an advantage in low exhaust noise. Better thermal efficiency, significantly lower CO and HC emissions were attained by hydrous ethanol gasoline at all operating conditions. However, significant NOx emission and slight brake specific fuel consumption (BSFC) were noticed for E10W and E20W. Comparing E10W with E20W, E10W showed that BSFC, HC and NOx emissions are decreased with the increase of engine speed, while CO emission was only slightly increased. Hence, hydrous ethanol gasoline can be considered as a promising alternative fuel for SI engine.

This study is an ongoing work that investigates exhaust emissions and provides gasoline engines with gasoline fuel. Early empirical results clearly demonstrated that NOx engine emissions are reduced after syngas rich in hydrogen from the plasma-assisted fuel adapter has been added to the staff fork of the tested engine. An extremely significant decrease in harmful pollution was observed for lean conditions. Continuing this work, investigations of ultra-lean systems have been implemented. This study investigates the effect a stoichiometric mixture regime in the presence of 5 and 10 vol.\% anhydrous ethanol-gasoline blended fuel (E5 and E10) and hydrous ethanol-gasoline (HE5 and HE10 with water concentration $=5 \%, 10 \%, 30 \%$ and $40 \%)$ on two types of fuel available in the Saudi Arabian gasoline market: RON91 and RON95.

\section{Materials and Methods}

The test bench used in this study consisted of four supported systems: modified gasoline engine, feeding, plasma, and load systems. A Subaru EH72 FI gasoline engine with a fuel injection system was used in the experiments. Table 1 explains the technical specifications of the engine. Table 2 lists properties and constituents of Saudi Arabia's RON 91 and RON 95 sample [18]. Figure 1 illustrates a schematic diagram of the experiments, while Figure 2 shows the test bench. A specifically developed engine control unit (ECU) was modified, and a Bosch HFM5 flow metre from Bush was installed in the suction channel of the engine for precise measurement of airflow. Two original built-in fuel injectors were operated electronically by the ECU metre fuel. A Hitec HS635HB servo was installed and connected to the throttle arm to control the computer from the throttle position. The exhaust emissions $\left(\mathrm{CO}_{2}, \mathrm{CO}, \mathrm{NOx}\right.$, and $\left.\mathrm{HC}\right)$ and $\mathrm{O}_{2}$ concentrations were monitored using an automotive INFRACAR 5M3T.01 exhaust gas analyser. While loading the engine, an Enders ESE 1506 DSG-GT ES 
DUPLEX SSG 132 Medium power electric generator was used, and along the engine shaft, the load was adjusted by choosing the number of heaters connected to the generator. The fuel adapter for generating syngas consisted of a plasma discharge unit and a reactor. Figure 3 shows a diagram of the plasma discharge chamber. The plasmatron cathode is a copper electrode that is cooled with water by a tungsten rod inserted into the copper tip. A high-voltage DC power source from Technix, an SR10-(P/N/R), was used to operate the plasmatron in arc flux to position the transition from discharge at approximately atmospheric pressure. The power supply ensures a maximum output voltage of $10 \mathrm{kV}$, and the current is operated at any required level in a range of 0 to $500 \mathrm{~mA}$. Adding steam to the fuel mixture helps to avoid soot formation during the gasoline repair process. Figure 4 shows a schematic of the plasmatron fuel mixing and evaporation unit.

Table 1. Technical specifications of the engine.

\begin{tabular}{cc}
\hline Description & Specification \\
\hline Type & Air-Cooled, 4-Stroke, V-Twin Cylinder, Horizontal \\
Pore $\times$ Stroke, $\mathrm{mm}$ & $84 \times 65$ \\
Displacement, $\mathrm{cm}^{3}$ & 720 \\
Compression ratio & 8.1 \\
Continuous output, $\mathrm{kW}(\mathrm{HP}) /$ r.p.m. & $14.9(20.0) / 3600$ \\
Maximum torque, Nm/r.p.m. & $52.2 / 2800$ \\
Charging capacity, V - A & $12-15$ or $12-30$ (Option) \\
\hline
\end{tabular}

Table 2. Properties and constituents of Saudi Arabia's RON 91 and RON 95 sample.

\begin{tabular}{ccc}
\hline Description & RON 91 & RON 95 \\
\hline Calculate octane number & 90.44 & 94.66 \\
Initial boiling point (C) & 39 & 35.7 \\
Final boiling point (C) & 204 & 197.2 \\
Relative density & 0.679 & 0.688 \\
Vapor pressure (kPa @ 37.8 C) & 36.75 & 39.58 \\
Lower heating value (kJ/kg) & 43.932 & 43.304 \\
Constituents (\% mass) Paraffins & 10.544 & 9.033 \\
I-paraffins & 36.853 & 37.500 \\
olefin & 13.911 & 13.373 \\
Naphthenes & 5.665 & 10.427 \\
Aromatic & 28.870 & 24.961 \\
Total C14+ & 0 & 0.096 \\
Total unknown & 1.752 & 2.269 \\
Total & 100 & 100 \\
\% Carbon & 86.045 & 86.413 \\
\% Hydrogen & 13.156 & 13.163 \\
H/C & 0.153 & 0.152 \\
Average molecular weight & 85.571 & 88.288 \\
\hline
\end{tabular}




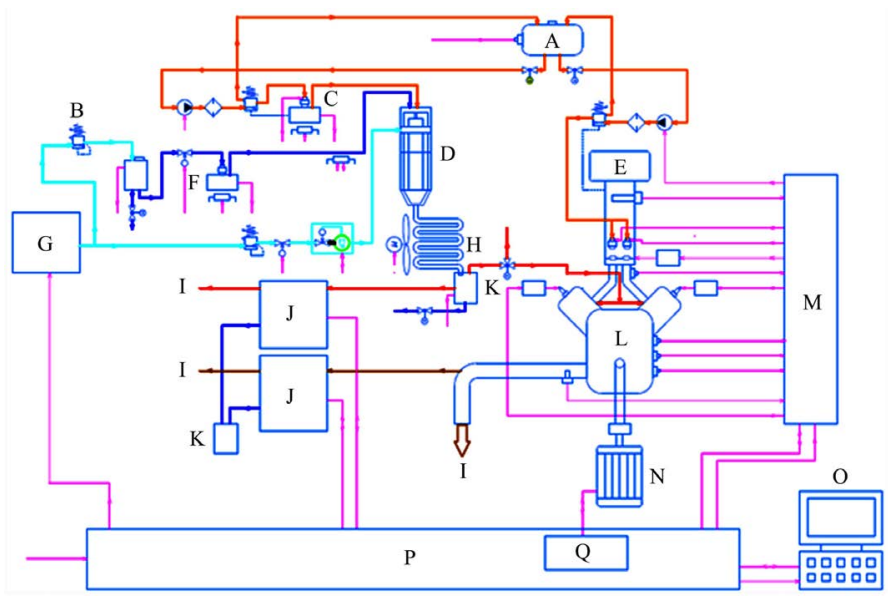

Figure 1. Schematic of the experimental setup showing: (A) Fuel Tank, (B) Pressure Regulator, (C) Fuel Evaporator, (D) Plasma Converter, (E) Air Filter, (F) Water Evaporator. (G) Air Compressor, (H) Chiller, (I) Exhaust, (J) Gas Analyser, (K) Condensate Tank, (L) Engine, (M) ECU, (N) Electric Generator, (O) PC, (P) Stand CU, (Q) Inverter.
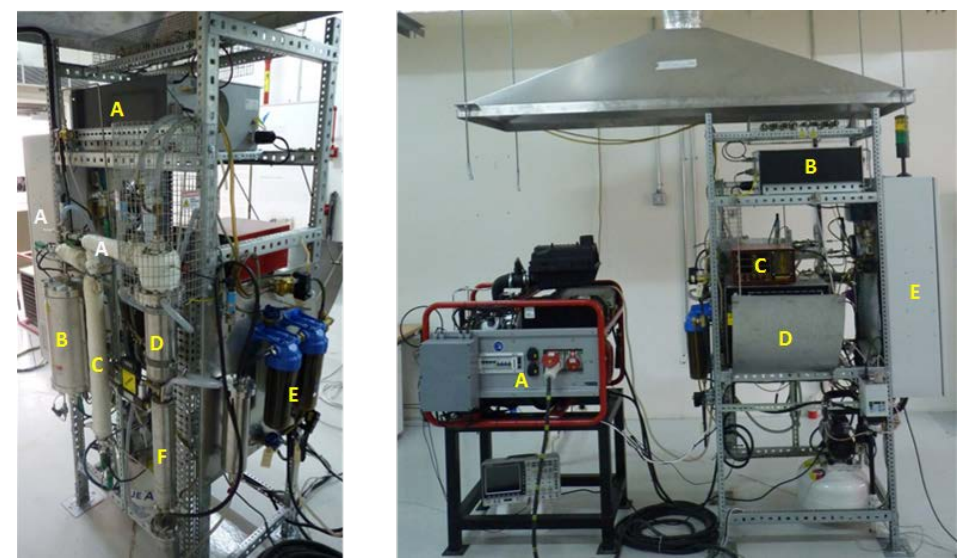

Figure 2. Left: Rear view of the test bench showing: (A) Power Supply, (B) Boiler, (C) Air Heater, (D) Reactor, (E) Filters, (F) Cooler. Right: Front view of the test bench showing: (A) Engine, (B) Power Supply, (C) Engine Gas Analyser, (D) Chiller, (E) Main Control Box.

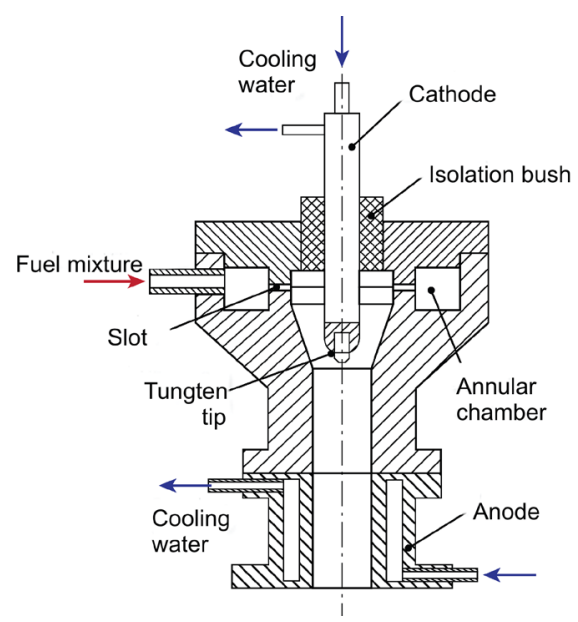

Figure 3. Discharge unit of the plasma converter. 


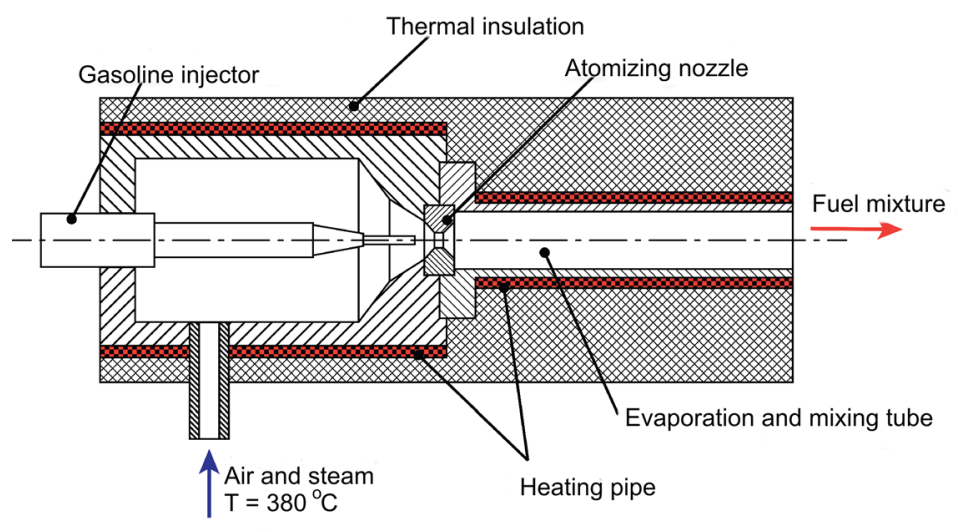

Figure 4. Schematic of the plasmatron fuel mixing and evaporation unit.

The evaporation of gasoline droplets was performed in the mixing tube located downstream of the pitchforking nozzle. This tube is an electrically heated section of a stainless steel tube with an internal diameter of $8 \mathrm{~mm}$ and a length of $260 \mathrm{~mm}$. The steam generator consists of a hot electric boiler and a high-pressure superheater with a pressure range from 3.5 bar to 6 bar. An Omega 5400 mass flow controller and an ISMATEC REGLO-CPF flow pump control the mass flow rate of air and the gasoline used to produce the rich syngas in the plasma reformer, respectively. The experimental studies were carried out at a speed of $2700 \mathrm{rpm}$ at stoichiometric air/fuel ration mixture $(\lambda=1.0)$. Plasma system operation parameter optimization was performed to obtain the maximum hydrogen content for both gasoline types (RON 91 and RON95), such as hydrogen yield, total gas flow rate, steam flow rate, and initial mixture composition dependences. The pressure in the boiler was fixed at $0.3 \mathrm{MPa}$, and the fuel flow rate was $4 \mathrm{~g} / \mathrm{min}$. The ignition advance (ignition timing) was at $15^{\circ}$. More than 500 runs with various electrical power loads were conducted. Engine rendering was in comparison to two types of fuel: a usual air-gasoline mixture and an air-gasoline mixture with syngas. During the experiments, the cooler for the plasma conversion products was given a new design due to the formation of a solid carbonic plug that made the cooler coils impermeable. Several unsuccessful attempts were made to dissolve the carbonic plug using various solvents such as acetone, dioxin, and gasoline. Therefore, a new design was made to increase and overhaul the life of the new cooler for the conversion products.

\section{Results and Discussion}

NOx emission content and fuel consumption are influenced by blending gasoline fuel (RON91 or RON95) with ethanol (E5 and E10) and hydrous ethanol (HE5 and HE10) at different water concentrations (W.C. $=5 \%, 10 \%, 30 \%$ and $40 \%$ ). Discussion in detailed is following for both cases of injecting and without injecting of the syngas to the engine. The reduction of NOx emissions content due to using of hydrous ethanol (HE) and syngas can be attributed to decreased combustion and engine temperature by the effect of presence of water vapour in 
the mixture, where lower combustion temperature yields lower generation of NOx emissions. Slight increasing of fuel consumption due to using hydrous ethanol and syngas can be justified as part of combustion energy, which is consumed to vaporize the non-completely vaporized water in the fuel mixture. Table 3 displays maximum NOx emissions reduction (ppm) during the experiment at water concentration of $40 \%$ volume of hydrous ethanol.

\subsection{NOx Emissions: Gasoline, Anhydrous Ethanol and Hydrous Ethanol without Syngas}

Figure 5 and Figure 6 show NOx emissions for gasoline RON91 and gasoline RON95, respectively, with blend conditions: E5 and HE5 (at water concentrations $5 \%, 10 \%, 30 \%$ and $40 \%$ ) without injecting of syngas to the engine. NOx emissions reduced significantly when using E5. Moreover, when adding HE5 with different water concentrations, NOx emissions increased at the case of water concentration 5\%, while, NOx emissions decreased gradually with the increase of water concentration from $10 \%$ to $40 \%$ at the low-range and mid-range of load for both RON91 and RON95, where lowest NOx emissions were found to be a water concentration of $40 \%$. At the high-range load, lowest emissions content was at HE5 with a water concentration of $10 \%$.

Figure 7 and Figure 8 show NOx emissions for emissions for gasoline RON91 and gasoline RON95, respectively, with blend conditions: E10 and HE10 (at water concentrations $5 \%, 10 \%, 30 \%$ and $40 \%$ ) without injecting of syngas to the engine. NOx emissions reduced significantly when using E10. Furthermore, when adding HE510 with different water concentrations, NOx emissions increased at the case of water concentration 5\%, while, NOx emissions decreased gradually with the increase of water concentration from $10 \%$ to $40 \%$ at the low-range and mid-range of load for both RON91 and RON95, where lowest NOx emissions were found to be a water concentration of $40 \%$. At the high-range load, lowest emissions content was at HE10 with a water concentration of $30 \%$.

Table 3. Maximum NOx emissions reduction (ppm) for engine speed of $2700 \mathrm{RPM}$ at maximum load of $10 \mathrm{~kW}$ for each fuel types of gasoline Ron 91 and 95 at water concentration of $40 \%$ volume of hydrous ethanol.

\begin{tabular}{ccccccc}
\hline \multicolumn{7}{c}{ Fuel Types } \\
\hline & \multicolumn{3}{c}{ Gasoline RON 91 } & \multicolumn{3}{c}{ Gasoline RON 95 } \\
\hline & $\begin{array}{c}\text { Without } \\
\text { syngas } \\
(\mathrm{ppm})\end{array}$ & $\begin{array}{c}\text { With } \\
\text { syngas } \\
(\mathrm{ppm})\end{array}$ & $\begin{array}{c}\text { NOx } \\
\text { Reduction } \\
(\%)\end{array}$ & $\begin{array}{c}\text { Without } \\
\text { syngas } \\
(\mathrm{ppm})\end{array}$ & $\begin{array}{c}\text { With } \\
\text { syngas } \\
(\mathrm{ppm})\end{array}$ & $\begin{array}{c}\text { NOx } \\
\text { Reduction }\end{array}$ \\
\hline E0 & 1460 & 1006 & 31 & 1330 & 1060 & 20 \\
E0 + E & 660 & 500 & 24 & 700 & 550 & 21 \\
NOx Reduction in (\%) & 54 & 50 & - & 47 & 48 & - \\
E0 & 1460 & 1006 & 31 & 1330 & 1060 & 20 \\
E0 + HE (WC = 40 \%) & 650 & 400 & 38 & 490 & 300 & 39 \\
NOx Reduction in (\%) & 55 & 60 & - & 63 & 72 & -
\end{tabular}




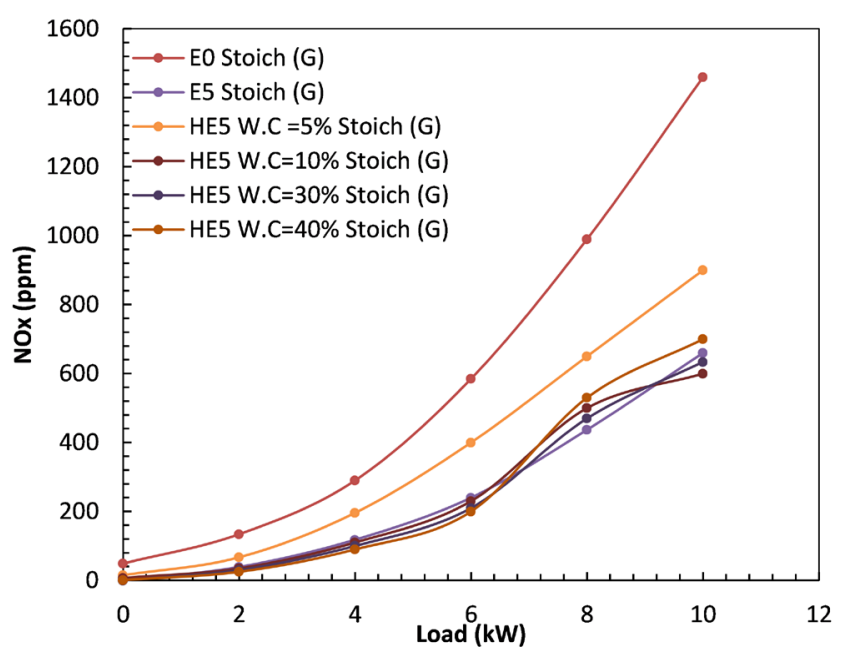

Figure 5. NOx emissions for E0-E5-HE5-Gasoline 91 octane number with different water concentrations at a stoichiometric mixture without syngas.

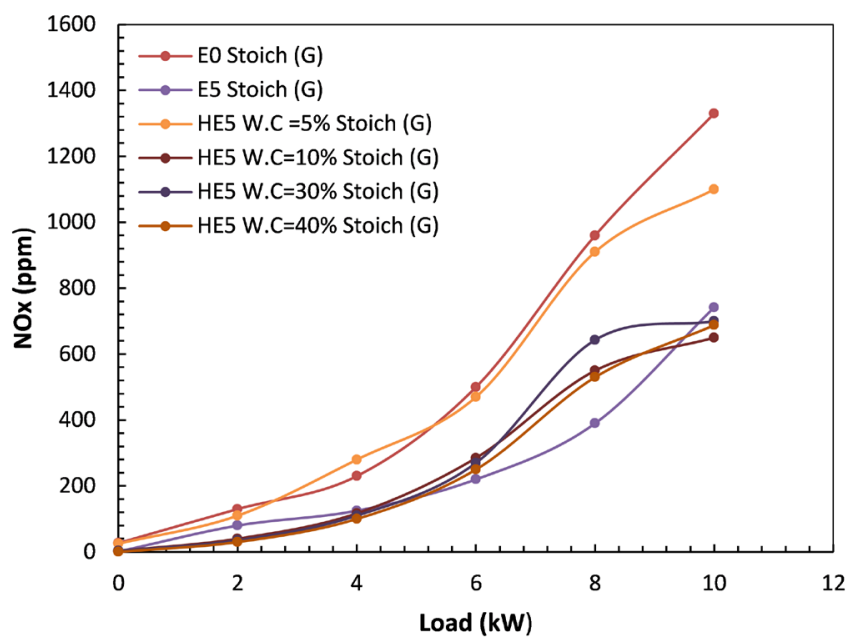

Figure 6. NOx emissions for E0-E5-HE5-Gasoline 95 octane number with different water concentrations at a stoichiometric mixture without syngas.

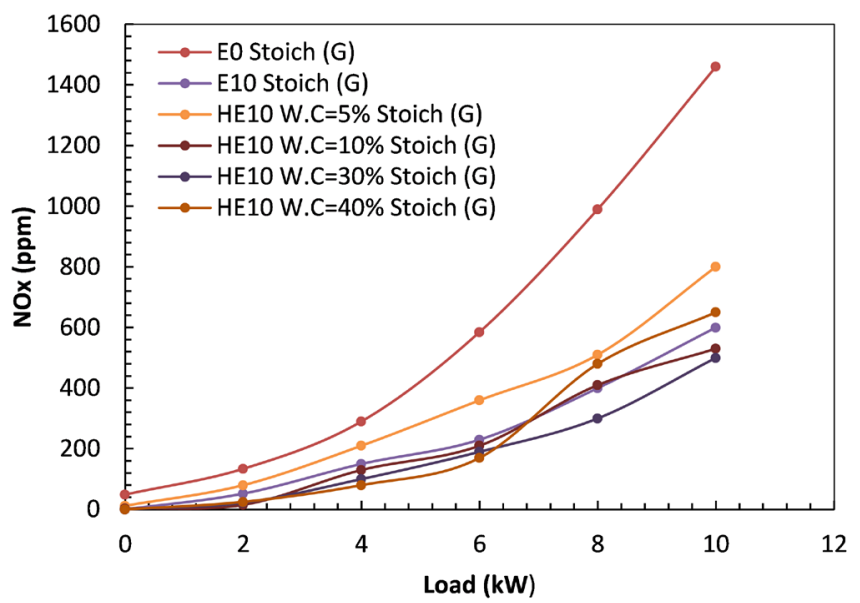

Figure 7. NOx emissions for E0-E10-HE10-Gasoline 91 octane number with different water concentrations at a stoichiometric mixture without syngas. 


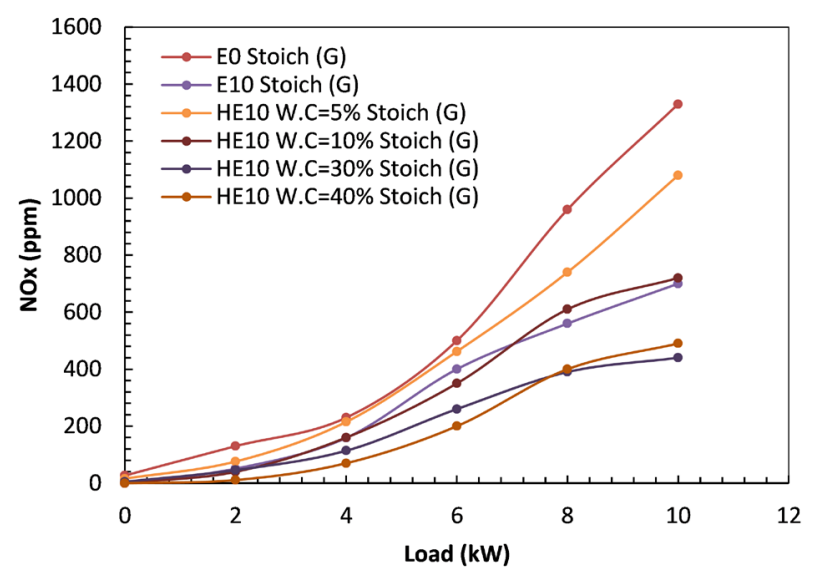

Figure 8. NOx emissions for E0-E10-HE10-Gasoline 95 octane number with different water concentrations at a stoichiometric mixture without syngas.

\subsection{NOX Emissions: Gasoline, Anhydrous Ethanol and Hydrous Ethanol with Syngas}

Effect of injecting the syngas with pure gasoline (E0) on emissions was demonstrated in a previous study, Al-Harbi et al. [14], where the NOx emissions were dramatically reduced. Figure 9 and Figure 10 show NOx emissions for gasoline RON91 and gasoline RON95, respectively, with blend conditions: E5 and HE5 (at water concentrations 5\%,10\%,30\% and $40 \%$ ) while the engine is injected with syngas at the same time. NOx emissions reduced significantly when using E5 along with adding syngas. Moreover, when adding HE5 with different water concentrations, NOx emissions increased at the case of water concentration 5\%, while, NOx emissions decreased gradually with the increase of water concentration from $10 \%$ to $40 \%$ at the low-range and mid-range of load for both RON91 and RON95, where lowest NOx emissions were found to be a water concentration of $40 \%$.

Figure 11 and Figure 12 show NOx emissions for gasoline RON91 and gasoline RON95, respectively, with blend conditions: E10 and HE10 (at water concentrations $5 \%, 10 \%, 30 \%$ and $40 \%$ ) while the engine is injected with syngas at the same time. NOx emissions reduced significantly when using E10 along with adding syngas. Moreover, when adding HE5 with different water concentrations, NOx emissions increased at the case of water concentration 5\%, while, NOx emissions decreased gradually with the increase of water concentration from $10 \%$ to $40 \%$ at the low-range and mid-range of load for both RON91 and RON95, where lowest NOx emissions were found to be a water concentration of $40 \%$.

\subsection{Fuel Consumption: Gasoline, Anhydrous Ethanol and Hydrous Ethanol without Syngas}

Figure 13 and Figure 14 show the fuel consumption for gasoline RON91 and gasoline RON95, respectively, with blend conditions: E5 and HE5 (at water concentrations 5\%, 10\%, 30\% and 40\%) without syngas. For RON91, fuel consump- 
tion decreases slightly when E5 is used low-range of load then increases in the mid-range and high-range of load. In addition, when using HE5 with different water concentrations, fuel consumption increases in general. For RON95 fuel consumption of E5 is, almost, the same as that of E0, where there is no significant change. Moreover, when using HE5 with different water concentrations, fuel consumption increases in general.

Figure 15 and Figure 16 show the fuel consumption for gasoline RON91 and gasoline RON95, respectively, with blend conditions: E5 and HE5 (at water concentrations $5 \%, 10 \%, 30 \%$ and $40 \%$ ) without syngas. When using E10, for both RON91 and RON95, the increase in fuel consumption grows as the load increases. Furthermore, when using HE10 with different water concentrations, fuel consumption increases in general for both RON91 and RON95 at all load ranges.

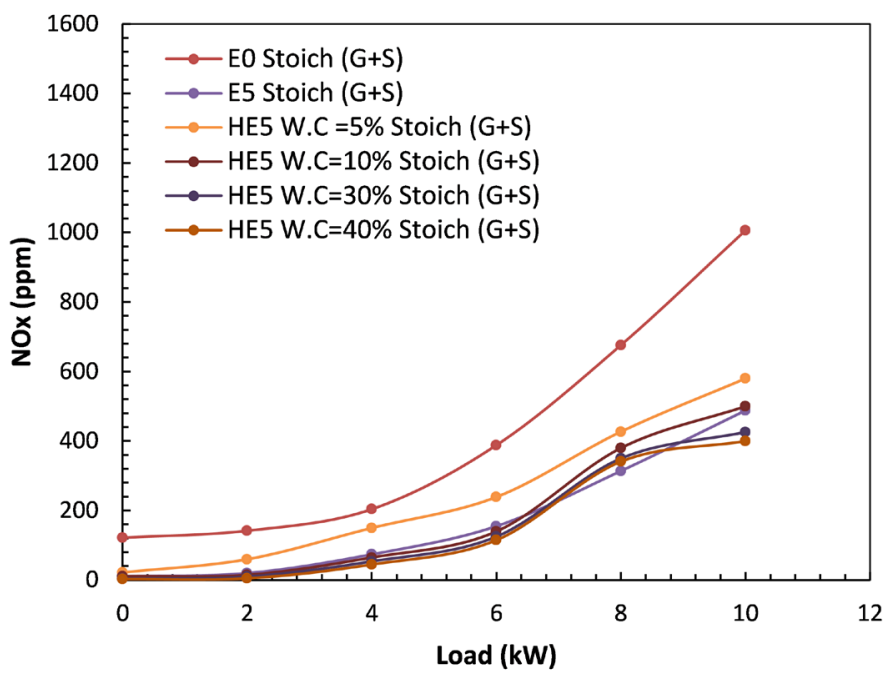

Figure 9. NOx emissions for E0-E5-HE5-Gasoline 91 octane number with different water concentrations at a stoichiometric mixture with syngas.

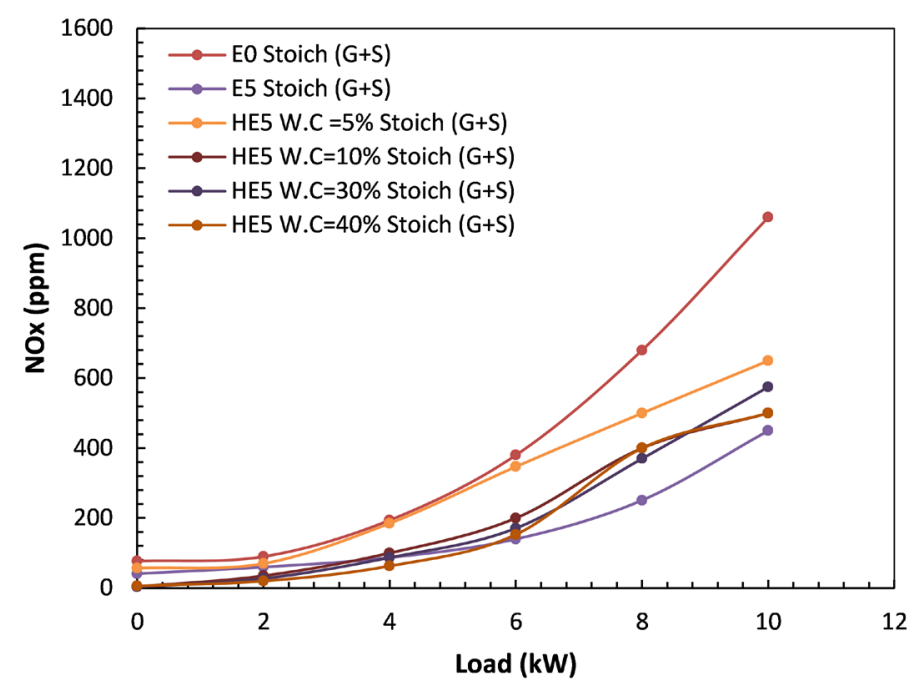

Figure 10. NOx emissions for E0-E5-HE5-Gasoline 95 octane number with different water concentrations at a stoichiometric mixture with syngas. 


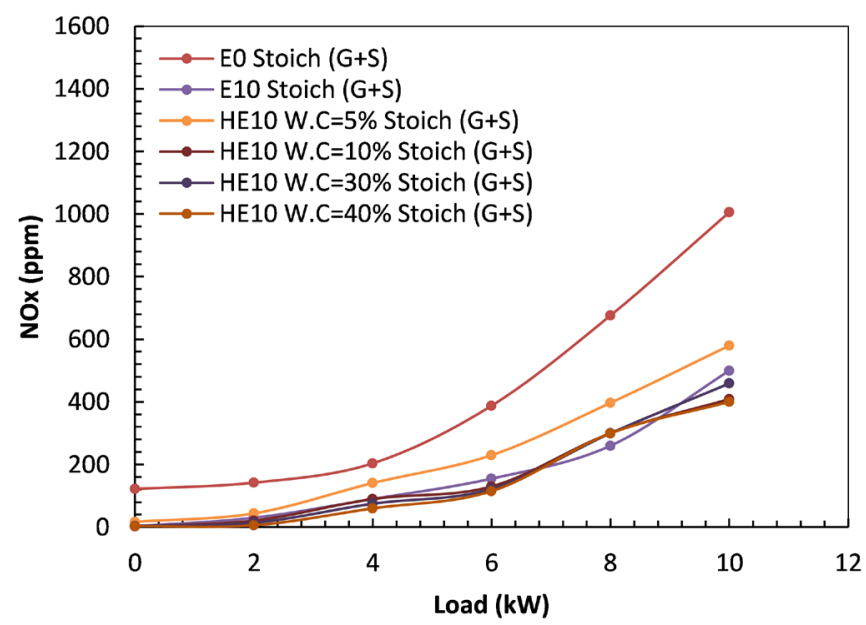

Figure 11. NOx emissions for E0-E10-HE10-Gasoline 91 octane number with different water concentrations at a stoichiometric mixture with syngas.

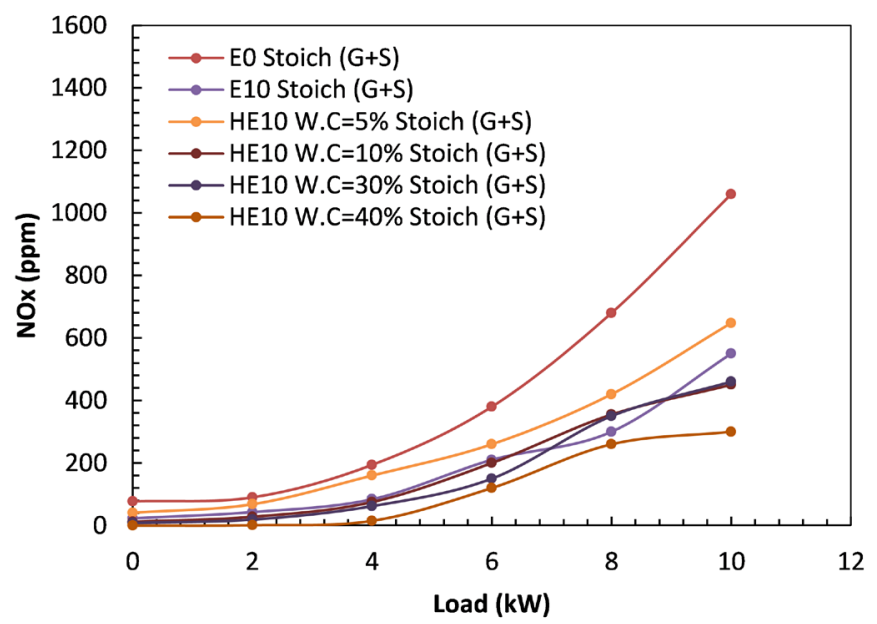

Figure 12. NOx emissions for E0-E10-HE10-Gasoline 95 octane number with different water concentrations at a stoichiometric mixture with syngas.

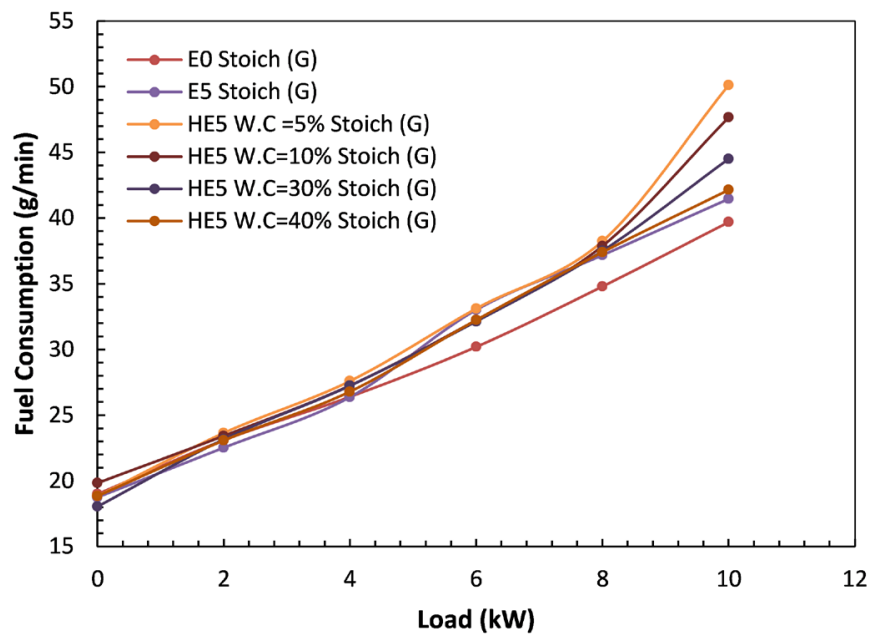

Figure 13. Fuel consumption of E0-E5-HE5-Gasoline 91 octane number with different water concentrations at a stoichiometric mixture without syngas. 


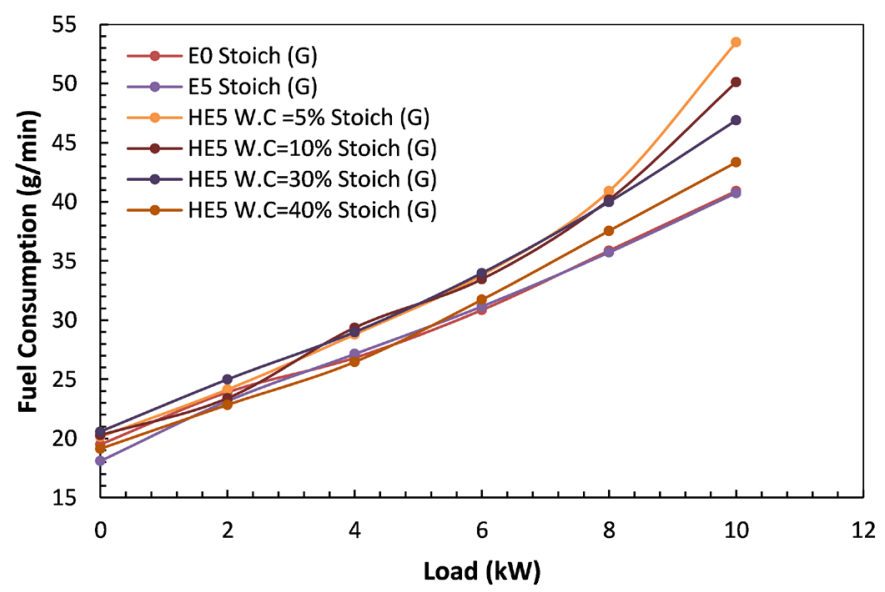

Figure 14. Fuel consumption of E0-E5-HE5-Gasoline 95 octane number with different water concentrations at a stoichiometric mixture without syngas.

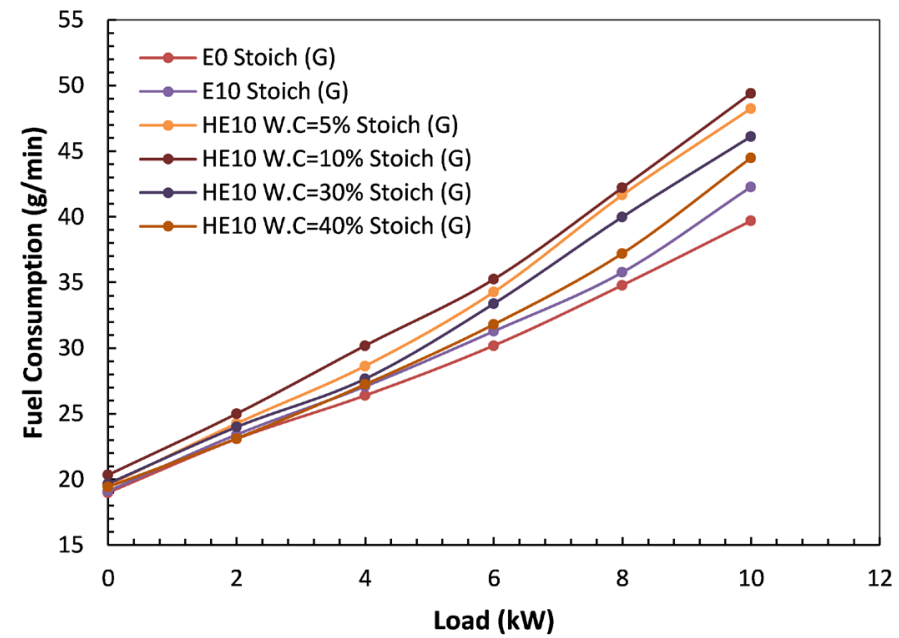

Figure 15. Fuel consumption of E0-E10-HE10-Gasoline 91 octane number with different water concentrations at a stoichiometric mixture without syngas.

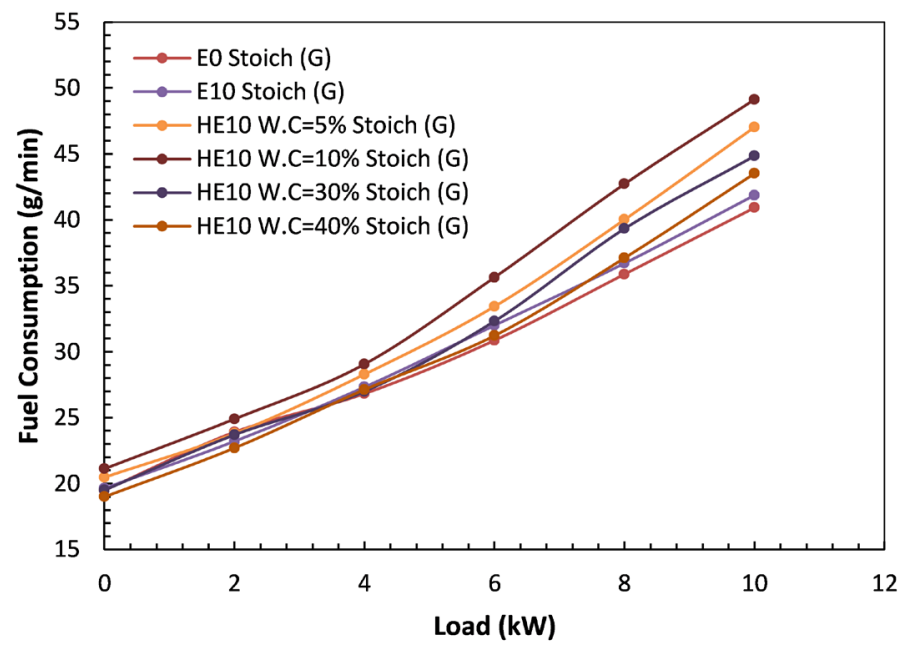

Figure 16. Fuel consumption of E0-E10-HE10-Gasoline 95 octane number with different water concentrations at a stoichiometric mixture without syngas. 


\subsection{Fuel Consumption: Gasoline, Anhydrous Ethanol and Hydrous Ethanol with Syngas}

Figure 17 and Figure 18 show the fuel consumption for gasoline RON91 and gasoline RON95, respectively, with blend conditions: E5 and HE5 (at water concentrations $5 \%, 10 \%, 30 \%$ and $40 \%$ ) while the engine is injected with syngas. For RON91, when using E5 with syngas, fuel consumption increases. Moreover, HE5 with different water concentrations with syngas decreased the fuel consumption at low-rage load, while it is increased, in general, at the mid and high-range of load. For RON95, using E5 with syngas decreases fuel consumption in general. As well as, fuel consumption is decreased, generally, for HE5 at different water concentrations with syngas.

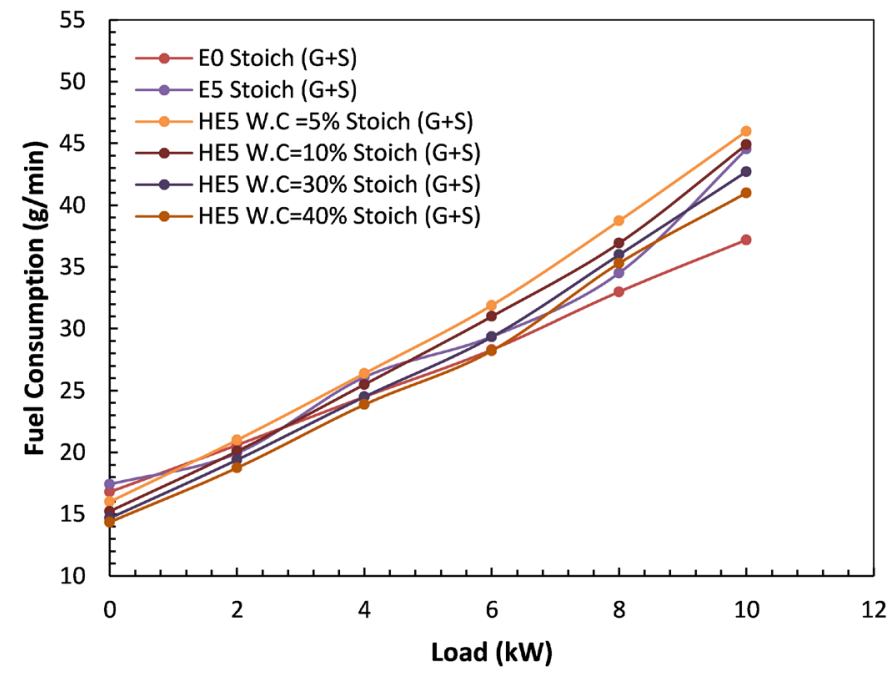

Figure 17. Fuel consumption of E0-E5-HE5-Gasoline 91 octane number with different water concentrations at a stoichiometric mixture with syngas.

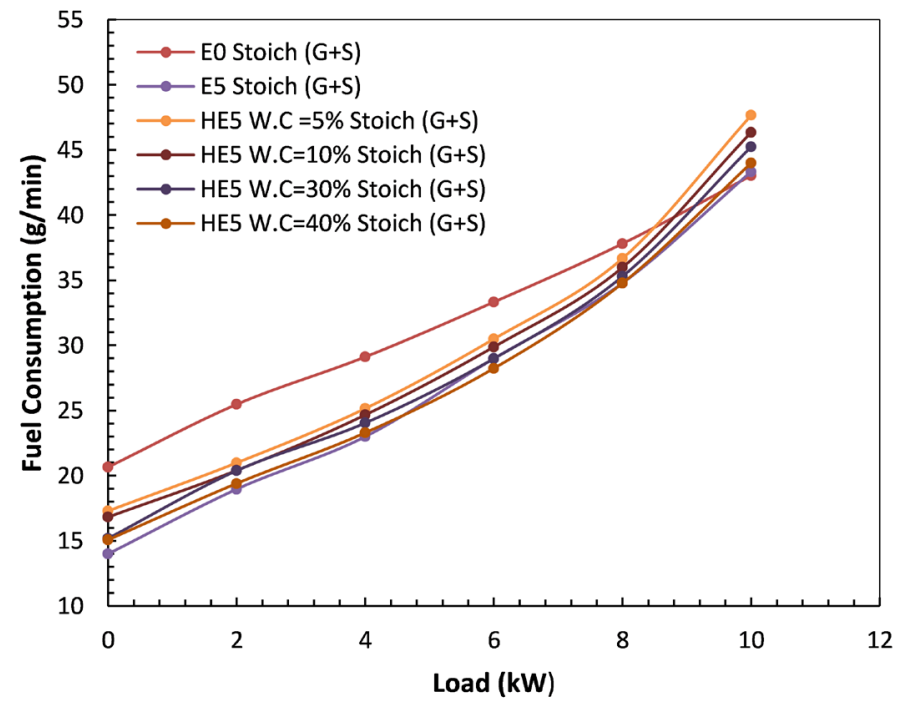

Figure 18. Fuel consumption of E0-E5-HE5-Gasoline 95 octane number with different water concentrations at a stoichiometric mixture with syngas. 
Figure 19 and Figure 20 show the fuel consumption for gasoline RON91 and gasoline RON95, respectively, with blend conditions: E5 and HE5 (at water concentrations $5 \%, 10 \%, 30 \%$ and $40 \%$ ) while the engine is injected with syngas. For RON91, when using E10 with syngas, the fuel consumption decreases at low and mid-range of load, then increases for a higher load. Additionally, HE10 with different water concentrations with syngas decreased the fuel consumption at low-rage load, while it is increased, in general, at the mid and high-range of load. For RON95, using E10 with syngas decreases fuel consumption in general. As well as, fuel consumption is decreased, generally, for HE10 at different water concentrations along with syngas.

\section{Conclusions}

This study investigates the effect of 5 and 10 vol.\% anhydrous ethanol-gasoline

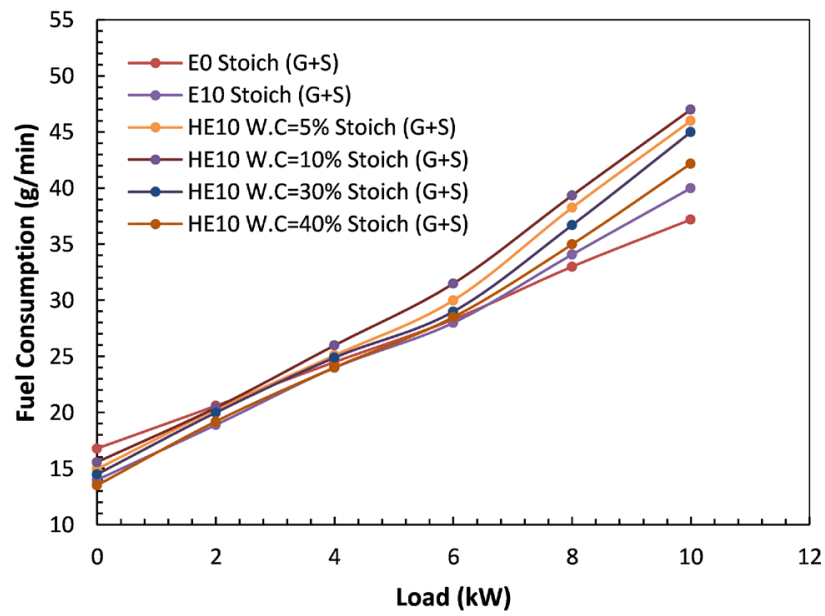

Figure 19. Fuel consumption of E0-E5-HE5-Gasoline 91 octane number with different water concentrations at a stoichiometric mixture with syngas.

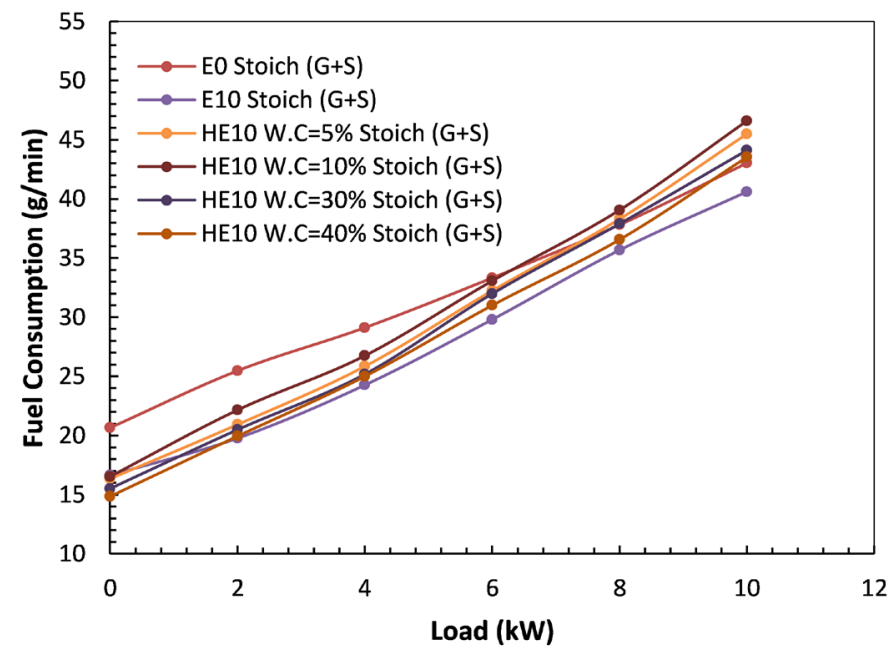

Figure 20. Fuel consumption of E0-E5-HE5-Gasoline 95 octane number with different water concentrations at a stoichiometric mixture with syngas. 
blended fuel (E5 and E10) and hydrous ethanol-gasoline (HE5 and HE10 with water concentrations $=5 \%, 10 \%, 30 \%$ and $40 \%)$ for two types of fuel: RON91 and RON95 on the emissions content and performance of SI engine operated at a stoichiometric mixture regime. The experimental results demonstrated a significant total reduction in NOx emissions and a slight change in fuel consumption-including fuel supplied to the plasma-assisted converter-when mixing gasoline (RON 91 or RON 95), ethanol (E5 and E10) and hydrous ethanol (HE5 and HE10) with syngas. The main finding regarding the plasma system and the engine operations can be summarized as follow:

1) Mixing gasoline, anhydrous ethanol and hydrous ethanol with and without syngas while supplying the engine had a positive effect on emissions content, where $N o_{x}$ was dramatically reduced and fuel consumption was slightly increased.

2) Blending gasoline (RON95 or RON91) with 5\% ethanol (E5) and $10 \%$ ethanol (E10) resulted in a considerable reduction in $\mathrm{No}_{x}$ content, where (E10) gave more reduction than (E5).

3) Blending gasoline (RON95 or RON91) with hydrous ethanol (HE5, HE10) at water concentrations of $5 \%, 10 \%, 30 \%$ and $40 \%$ resulted in a considerable reduction in $\mathrm{No}_{x}$ content.

4) As the water concentration increased in the hydrous ethanol-gasoline blend, $\mathrm{No}_{x}$ content decreased at the stoichiometric regimes of the engine for both cases of with and without syngas.

5) As the water concentration increased in the hydrous ethanol-gasoline blend, fuel consumption decreased, in general, at the stoichiometric regimes of the engine for both cases of with and without syngas.

6) Maximum $\mathrm{No}_{x}$ emissions reduction for blends of gasoline + ethanol + hydrous ethanol was found to be at water concentration $40 \%$, for both fuel types (RON91 or RON95) and both ethanol volume percentage (5\% and 10\%).

7) Water concentration $5 \%$ has a negative effect on $\mathrm{No}_{x}$ emissions content and fuel consumption for both HE5 and HE10 compared to those for E5 and E10, while they ( $N o_{x}$ and fuel consumption) trend again, positively, as the water concentration is increased $(10 \%, 30 \%$ and $40 \%)$ for both gasoline types (RON91 or RON95) with and without syngas.

\section{Acknowledgements}

The authors acknowledge the financial support from the Energy and Water Research Institute, King Abdulaziz City of Science and Technology, Project No. 33-906 "Development, construction and delivery of onboard plasma-based fuel reformer for higher IC engine efficiency".

\section{Conflicts of Interest}

The authors declare no conflicts of interest regarding the publication of this paper. 


\section{References}

[1] Gupta, P., Sae-wang, V., Kanbua, P. and Laoonual, Y. (2011) Impact of Water Contents Blended with Ethanol on SI Engine Performance and Emissions. Journal of Research and Applications in Mechanical Engineering, 1, 7-11. https://www.tci-thaijo.org/index.php/jrame/article/view/150231

[2] Truyen, P.H., Tuyen, P.H., Tuan, P.M. and Tuan, L.A. (2012) Influence of E10, E15 and E20 Fuels on Performance and Emissions of In-Use Gasoline Passenger Cars. ASEAN Engineering Journal Part C, 4, 33-40. http://seed-net.org/wp-content/uploads/2015/12/INFLUENCE-OF-E10-E15-ANDE20-FUELS-ON-PERFORMANCE-AND-EMISSIONS-OF-IN-USE-GASOLINE-P ASSENGER-CARS.pdf

[3] Masum, B.M., Masjuki, H.H., Kalam, M.A., Fattah, I.R., Palash, S.M. and Abedin, M.J. (2013) Effect of Ethanol-Gasoline Blend on NOx Emission in SI Engine. Renewable and Sustainable Energy Reviews, 24, 209-222. https://doi.org/10.1016/j.rser.2013.03.046

[4] Pal, A. (2014) Blending of Ethanol in Gasoline: Impact on SI Engine Performance and Emissions. International Journal of Thermal Technologies, 4, 1-5. https://inpressco.com/wp-content/uploads/2014/03/Paper11-52.pdf https://doi.org/10.14741/ijtt/mar.2014.01

[5] Volpato Filho, O. (2008) Gasoline C Made with Hydrous Ethanol. XVI SIMEA Simpósio Internacional de Engenharia Automotiva, São Paulo, 17 September 2008. https://www.researchgate.net/publication/309564235 GASOLINE_C MADE WIT H_HYDROUS ETHANOL

[6] Munsin, R., Laoonual, Y., Jugjai, S. and Imai, Y. (2013) An Experimental Study on Performance and Emissions of a Small SI Engine Generator Set Fuelled by Hydrous Ethanol with High Water Contents up to 40\%. Fuel, 106, 586-592. https://www.sciencedirect.com/science/article/pii/S0016236112011039 https://doi.org/10.1016/i.fuel.2012.12.079

[7] El-Faroug, M., Yan, F., Luo, M. and Fiifi Turkson, R. (2016) Spark Ignition Engine Combustion, Performance and Emission Products from Hydrous Ethanol and Its Blends with Gasoline. Energies, 9, 984. https://doi.org/10.3390/en9120984

[8] De Melo, T.C.C., Machado, G.B., Belchior, C.R., Colaço, M.J., Barros, J.E., de Oliveira, E.J. and de Oliveira, D.G. (2012) Hydrous Ethanol-Gasoline Blends-Combustion and Emission Investigations on a Flex-Fuel Engine. Fuel, 97, 796-804. https://doi.org/10.1016/j.fuel.2012.03.018

[9] Huang, D.Y., Lin, B.F. and Jang, J.H. (2015) Emission of Internal Combustion with Low Temperature Plasma Reformer. Energy Procedia, 75, 3036-3041. https://doi.org/10.1016/j.egypro.2015.07.618

[10] Opaliński, M., Rek, P. and Skrobek, W. (2014) Reforming Gaseous Fuels as a Method of Engine Combustion Process Improvement. http://sdpg.pg.gda.pl/pij/wp-content/blogs.dir/133/files/2014/12/01 2014 22-opalin ski mar.pdf

[11] Lee, J. and Castaldi, M.J. (2010) A Study on Performance and Emissions of a 4-Stroke IC Engine Operated on Landfill Gas with Syngas Addition. In: 18th Annual North American Waste-to-Energy Conference, American Society of Mechanical Engineers Digital Collection, Orlando, 11-13 May 2010, 61-67. https://doi.org/10.1115/NAWTEC18-3565

[12] Green Jr., J.B., Domingo, N., Storey, J.M.E., Wagner, R.M., Armfield, J.S., Bromberg, L., Alexeev, N., et al. (2000) Experimental Evaluation of SI Engine Operation 
Supplemented by Hydrogen Rich Gas from a Compact Plasma Boosted Reformer. SAE (Society of Automotive Engineers) Transactions, 109, 1875-1882.

https://www.jstor.org/stable/44634357? seq=1\#page scan tab contents https://doi.org/10.4271/2000-01-2206

[13] Bromberg, L., Cohn, D.R., Rabinovich, A. and Heywood, J. (2001) Emissions Reductions Using Hydrogen from Plasmatron Fuel Converters. International Journal of Hydrogen Energy, 26, 1115-1121. https://doi.org/10.1016/S0360-3199(01)00049-0

[14] Al-Harbi, A.A., Alenazey, F.S., Migoun, A.N., Dmitrenko, Y.M. and Zhdanok, S.A. (2016) Reducing Pollution Emissions by Adding Syngas Generated by a Plasma-Assisted Gasoline Converter in the Intake Manifold of a Gasoline Engine with Electronic Fuel Injection System. Heat Transfer Research, 47, 1073-1082.

http://www.dl.begellhouse.com/journals/46784ef93dddff27,4d60ef1c722bb89b,1cd6 8edd53d20305.html?sgstd=1 https://doi.org/10.1615/HeatTransRes.2016016579

[15] Alenazey, F.S., Al-Harbi, A.A., Chernukho, A.P., Dmitrenko, Y.M., Migoun, A.N. and Zhdanok, S.A. (2016) Syngas Production from Propane-Butane Mixtures Using a High-Voltage Atmospheric Pressure Discharge Plasma. Heat Transfer Research, 47, 1057-1072. https://doi.org/10.1615/HeatTransRes.2016016411 http://www.dl.begellhouse.com/journals/46784ef93dddff27,4d60ef1c722bb89b,184c 68f36e91f90d.html

[16] Hoang, A.T., Tran, Q.V., Al-Tawaha, A.R.M.S., Pham, V.V. and Nguyen, X.P. (2019) Comparative Analysis on Performance and Emission Characteristics of an In-Vietnam Popular 4-Stroke Motorcycle Engine Running on Biogasoline and Mineral Gasoline. Renewable Energy Focus, 28, 47-55.

https://www.sciencedirect.com/science/article/pii/S1755008418301236 https://doi.org/10.1016/j.ref.2018.11.001

[17] Deng, X., Chen, Z., Wang, X., Zhen, H. and Xie, R. (2018) Exhaust Noise, Performance and Emission Characteristics of Spark Ignition Engine Fuelled with Pure Gasoline and Hydrous Ethanol Gasoline Blends. Case Studies in Thermal Engineering, 12, 55-63. https://doi.org/10.1016/j.csite.2018.02.004 https://www.sciencedirect.com/science/article/pii/S2214157X17302708

[18] Binjuwair, S. and Alkudsi, A. (2016) The Effects of Varying Spark Timing on the Performance and Emission Characteristics of a Gasoline Engine: A Study on Saudi Arabian RON91 and RON95. Fuel, 180, 558-564.

https://doi.org/10.1016/j.fuel.2016.04.071 